\title{
The Effects of Nutrition and Environmental Factors on Conidial Germination and Appressorium Formation of Phyllosticta citricarpa, the Causal Agent of Citrus Black Spot
}

\author{
Nan-Yi Wang and Megan M. Dewdney ${ }^{\dagger}$ \\ Citrus Research and Education Center, University of Florida, Lake Alfred 33850. \\ Current address of N.-Y. Wang: Gulf Coast Research and Education Center, University of Florida, Wimauma 33598. \\ Accepted for publication 6 November 2018.
}

\begin{abstract}
Citrus black spot, caused by Phyllosticta citricarpa, has been identified in Florida since 2010 and can reduce fruit yield and marketability. The conditions required for conidial germination have been poorly understood for $P$. citricarpa, limiting further biological studies. In this study, the effects of citrus juices, concentration, $\mathrm{pH}$, various carbon and nitrogen sources, and environmental conditions were evaluated in vitro. All tested juices, especially 'Valencia' ( $>85 \%, P<0.05$ ), favored germination and appressorium formation, whereas sterile water rarely stimulated germination $(<1 \%)$. The 'Valencia' juice effect was concentration and $\mathrm{pH}$ dependent, and the maximum rate was reached in $1.5 \%$ juice with $\mathrm{pH}$ of

3.4. Most carbon, nitrogen, or complex sources did not favor germination or appressorium formation, with the exception of potato dextrose broth. An incubation period of 18 to $24 \mathrm{~h}$ at $24^{\circ} \mathrm{C}$ was required for peak germination and appressorium formation. The further analysis of critical juice components using synthetic citrus juice revealed that sugars, salts, citric acid, and thiamine were most important for germination and appressorium formation ( $>80 \%, P>0.05)$. These results provide a better understanding of fungal biology of $P$. citricarpa and a robust and convenient system for further applications such as screening for efficacious fungicides.
\end{abstract}

Citrus black spot, caused by Phyllosticta citricarpa (McAlpine) Aa (syn.: Guignardia citricarpa Kiely), is a common fungal disease in many subtropical citrus-producing areas, including Southeast Asia, Sub-Saharan Africa, South Africa, Australia, South America, and, most recently North America (Florida and Cuba) (Hidalgo Góngora and Pérez Vicente 2010; Kotzé 1981; Paul et al. 2005; Schubert et al. 2012; Yonow et al. 2013). Although Mediterranean citrus-growing regions remain disease free, the presence of $P$. citricarpa has been reported (Guarnaccia et al. 2017). This disease affects all commercial citrus cultivars, of which lemon (Citrus limon) is most susceptible (Baldassari et al. 2008; Kotzé 1981). Not only can citrus black spot depreciate fresh citrus fruit in the market due to the superficial fruit symptoms but it also can substantially reduce the yield due to immature fruit drop under high disease pressure (de Goes et al. 2000; Kiely 1948, 1949; Kotzé 1981), which threatens the juice-processing industry in Florida (Schubert et al. 2012). Moreover, citrus black spot has attracted tremendous attention due to trade restrictions on the fresh fruit export within the United States and globally because citrus black spot is considered as an A1 quarantine disease by the European and Mediterranean Plant Protection Organization (CBS Expert Panel 2013). Extra measures to export citrus from disease-infested areas to Europe would be essential and costly (EFSA 2014).

$P$. citricarpa infects plants by means of ascospores and pycnidiospores (conidia). Ascospores as the source of primary inoculum are produced in leaf litter on the floor of orchards under

†Corresponding author: M. M. Dewdney; E-mail: mmdewdney@ufl.edu

Funding: We sincerely thank the Citrus Research and Development Foundation (grant numbers 411 and 715) and Citrus Initiative for their funding support.

*The $\boldsymbol{e}$-Xtra logo stands for "electronic extra" and indicates that one supplementary figure and one supplementary table are published online.

The author(s) declare no conflict of interest.

(c) 2019 The American Phytopathological Society periodic wetting and drying events that correspond to the weather pattern in the rainy season (Kotzé 1981; Lee and Huang 1973; Reis et al. 2006). After maturity, ascospores are forcibly ejected from the moistened pseudothecia and disseminated to susceptible host tissue (leaves, twigs, and immature fruit) by wind currents over long distances $(<24.7 \mathrm{~m})$ (Spósito et al. 2007). Under favorable conditions such as the presence of moisture, ascospores initiate the infection process by germinating, forming appressoria, and directly penetrating the cuticle layer following successful attachment onto host tissue (Kotzé 1981; McOnie 1967). P. citricarpa remains quiescent in the subcuticular region for a long period until conditions such as senescence of leaves or ripeness of fruit favor the subsequent development of the fungus (Kotzé 1981; McOnie 1967). Conidia are considered a source of secondary inoculum and are produced on lesions of symptomatic fruit, on dead twigs, and in the leaf litter (Spósito et al. 2011; Whiteside 1967). Conidia have been documented to play an important role in the disease spread within tree canopies in Brazil and Zimbabwe (previously called Rhodesia), where infections were attributed to conidial inoculum from latehanging or out-of-season symptomatic fruit and dead twigs even in the presence of ascospore inoculum (Spósito et al. 2011; Whiteside 1967). However, according to studies originally conducted in Australia and South Africa, ascospores were predominantly responsible for the disease epidemic (Kiely 1949; Kotzé 1981; McOnie 1964; Spósito et al. 2008, 2011).

In the case of Florida, evidence from mating type and population genetic analyses across 113 P. citricarpa isolates suggested the presence of a clonal population of $P$. citricarpa harboring a single mating type in Florida (Wang et al. 2016). These findings were confirmed by Carstens et al. (2017) and indicate that the sexual reproduction of $P$. citricarpa is unlikely to occur in Florida (Wang et al. 2016). As a consequence, $P$. citricarpa conidia produced on fruit lesions, leaves, and dead twigs and in the leaf litter would be the sole inoculum source contributing to the epidemiology of citrus black spot in Florida (Carstens et al. 2017; Wang et al. 2016).

The first step of successful infection and colonization of host tissue by fungal pathogens is the attachment of spores to host tissue, 
followed by germination, appressorium formation, and penetration via an infection peg (Gareth Jones 1994). These processes are affected by many factors such as surface wettability, nutrients, and environmental conditions (incubation period, temperature, $\mathrm{pH}$, and so on) (Blank and Murray 1998; Emmett and Parbery 1975; Kuo and Hoch 1996; Liu and Xiao 2005). However, conditions required for these processes have been poorly understood for $P$. citricarpa, which limits further biological studies. Previously, Shaw et al. (2006) reported that conidia of Phyllosticta spp. germinated at significantly higher rates on hydrophobic surfaces, indicating a common phenomenon of the contact and attachment among Phyllosticta spp. prior to germination. For P. citricarpa, conidial germination was found to occur neither on artificial media such as water agar or potato dextrose agar (PDA) nor in sterile water on a hydrophobic surface (Darnell-Smith 1918; Kiely 1948; Korf 1998), implying the requirement of additional stimuli for conidial germination. Darnell-Smith (1918) first reported that orange peel extract had the capacity to stimulate conidial germination of freshly discharged $P$. citricarpa conidia in 12 h. Kiely (1948) further tested the capabilities of extracts of various fruit tissue at different ages for germination and proposed that some organic acids might play an important role in stimulating conidial germination. Afterward, he tested some organic acids (citric acid, tartaric acid, lactic acid, and oxalic acid) for stimulating germination and found that 0.1 to $0.5 \%$ citric acid greatly improved conidial germination to over $80 \%$. However, such a high germination rate of $P$. citricarpa conidia in citric acid solutions has not been repeated by other laboratories (Korf 1998), including our own. Furthermore, Korf (1998) reported that the addition of $2 \%$ 'Valencia' juice into the conidial suspension of $P$. citricarpa drastically increased the germination rate to approximately $60 \%$ after $48 \mathrm{~h}$ of incubation at $22^{\circ} \mathrm{C}$ on a hydrophobic surface. However, 'Valencia' juice is a complex solution and critical components in 'Valencia' juice required for $P$. citricarpa germination have not been determined. Moreover, the quality of 'Valencia' juice depends on the maturity of the fruit, which may greatly influence the subsequent assays of conidial germination and hamper the reproducibility of the experiments.

Therefore, in the present study, our objectives were to investigate the effects of (i) citrus juice sources, concentration, and $\mathrm{pH}$; (ii) incubation period and temperature; (iii) carbon and nitrogen sources; and (iv) synthetic citrus juice on conidial germination and appressorium formation of $P$. citricarpa. Our results contribute to a further understanding of nutritional and environmental factors required for the germination processes of $P$. citricarpa pycnidiospores and to the development of a robust and convenient system for the evaluation of fungicide efficacy.

\section{MATERIALS AND METHODS}

Culture, growth condition, and preparation of conidial suspensions. A single-spore isolate of $P$. citricarpa $\mathrm{Gc} 3$ which was isolated from a symptomatic fruit of 'Valencia' sweet orange from Immokalee, FL was used throughout the study after confirmation of yellow pigment production on oatmeal agar (Baayen et al. 2002; Schubert et al. 2012) and specific amplification using speciesspecific primers (Peres et al. 2007). P. citricarpa Gc3 was maintained on half-strength PDA (1/2PDA; Difco, Sparks, MD, U.S.A.) at $24^{\circ} \mathrm{C}$ under a cycle of $12 \mathrm{~h}$ of light and $12 \mathrm{~h}$ of darkness. To harvest conidia of $P$. citricarpa, 2- to 3-week-old cultures were flooded with a $0.02 \%$ Tween-20 solution ( vol/vol) (Hincapie et al. 2014). The resulting conidial suspension was then dispensed into 1.5-ml Eppendorf tubes and centrifuged at 2,500 $\times g$ for $5 \mathrm{~min}$. After discarding the supernatant, the pellet was resuspended in $1 \mathrm{ml}$ of sterile water. This washing step was repeated two more times. The final conidial suspension was counted with a hemocytometer (Bright Line; Hausser Scientific, Horsham, PA, U.S.A.) under an Olympus BX41 microscope (Olympus, Center Valley, PA, U.S.A.) at $\times 200$ magnification and adjusted to a concentration of at least
$10^{6}$ conidia/ml for the subsequent assays of conidial germination and appressorium formation.

Evaluation and observation of conidial germination. Unless otherwise specified, the conidial suspensions in this study were mixed with various solutions at a 1:3 ratio and pipetted onto 12-well Teflon-coated hydrophobic slides ( $5 \mu \mathrm{l} /$ well) (Thermo Fisher Scientific, Waltham, MA, U.S.A.). These slides were then placed onto moist P5 filter paper (Thermo Fisher Scientific) in petri dishes sealed with Parafilm to maintain the moisture. Petri dishes were transferred into a plastic moist chamber and incubated at $24^{\circ} \mathrm{C}$ for $24 \mathrm{~h}$. In total, 100 conidia were counted in each of five replicates for each experiment using an Olympus BX41 microscope (Olympus) at $\times 400$ magnification. All experiments were performed three times. The sterile deionized water and 2\% (vol/vol) 'Valencia' juice were used as negative and positive controls, respectively. The definition of a germinated conidium was that the conidium formed an appressorium or the length of the germ tube was equal to or greater than the width of the conidium. Images of the observations were acquired using a Leica DMR-HC microscope (Leica, Wetzlar, Germany) equipped with differential interference contrast optics and a SPOT digital camera (version 3.2; Diagnostic Instruments Inc., Sterling Heights, MI, U.S.A.) at 30-min intervals until the processes of conidial germination were complete. To be consistent across the study, germination data were considered when the percent conidial germination in $2 \%$ 'Valencia' juice (positive controls) achieved at least $80 \%$.

Effects of citrus juice sources, concentration, and pH. To determine conidial germination and appressorium formation of $P$. citricarpa in response to different nutritional environments, fresh fruit juice was squeezed from seven citrus cultivars in June 2010, including 'Valencia' sweet orange (C. sinensis (L.) Osbeck), 'Hamlin' sweet orange (C. sinensis (L.) Osbeck), 'Navel' sweet orange (C. sinensis (L.) Osbeck), 'Dancy' tangerine (C. tangerine Tanaka), 'Marsh' grapefruit (C. paradisi MacFadyen), 'Eureka' lemon (C. limon (L.) Burm. f. Eureka), and 'Key' lime (C. aurantifolia (Christm.) Swingle), followed by filtering with P5 filter paper (Thermo Fisher Scientific), and stored at $-20^{\circ} \mathrm{C}$ as stocks. Each juice stock was then diluted to $2 \%$ (vol/vol) and filter sterilized through $0.45-\mu \mathrm{m}$ membrane filters before use in assays. The $\mathrm{pH}$ of each diluted juice was also measured using an Accumet $\mathrm{pH}$ Meter AB15 (Thermo Fisher Scientific). To determine the optimal juice concentration for germination and appressorium formation of $P$. citricarpa, a series of 'Valencia' juice solutions with concentrations of $0.5,1.0,2.0,4.0,8.0$, and $16.0 \%$ (vol/vol) were prepared and used as above, resulting in the final concentrations of $0.375,0.75,1.5,3.0,6.0$, and $12.0 \%$ (vol/vol), respectively. To evaluate the relationship between the $\mathrm{pH}$ of the juice solution and germination processes, $\mathrm{pH}$ of $2 \%$ 'Valencia' juice was adjusted from 2 to 9 at $1-\mathrm{pH}$ intervals with $1 \mathrm{~N} \mathrm{HCl}$ or $1 \mathrm{~N} \mathrm{NaOH}$ using an Accumet pH Meter AB15 (Thermo Fisher Scientific). Afterward, 'Valencia' juice solutions with various $\mathrm{pH}$ levels were filter sterilized through $0.45-\mu \mathrm{m}$ membrane filters (Thermo Fisher Scientific) and applied as above.

To further determine the optimal $\mathrm{pH}$ of 'Valencia' juice for germination and appressorium formation, the $\mathrm{pH}$ of $2 \%$ 'Valencia' juice was adjusted from 3 to 5 at 0.2 -pH intervals with $1 \mathrm{~N} \mathrm{HCl}$ or $1 \mathrm{~N} \mathrm{NaOH}$, followed by filter sterilization using $0.45-\mu \mathrm{m}$ membrane filters (Thermo Fisher Scientific) and application to the germination tests as above.

Juice quality. To analyze juice quality, total soluble solids ( ${ }^{\circ}$ Brix), total titratable acid, and oil levels were determined according to Procedures for Analysis of Citrus Products published by FMC FoodTech (Cheng 2002). Briefly, measurements of ${ }^{\circ}$ Brix values of various juice samples were performed in triplicate using a digital Leica Mark II Plus Abbe refractometer (Leica). Acidity was determined by titrating $25 \mathrm{ml}$ of juice with $0.3123 \mathrm{~N} \mathrm{NaOH}$ to the end point of phenolphthalein. The amount of oil in each juice sample was determined based on the Scott oil analysis (Cheng 2002). 
Effects of temperature and incubation time. To determine the optimal temperature required for conidial germination and appressorium formation of $P$. citricarpa, conidial suspensions were prepared as above, mixed with $2 \%$ 'Valencia' juice at a 1:3 ratio, and applied to hydrophobic slides (Thermo Fisher Scientific). Petri dishes with slides were placed in plastic moist chambers and incubated at $4{ }^{\circ} \mathrm{C}$ intervals from 4 to $32^{\circ} \mathrm{C}$ for $24 \mathrm{~h}$. In addition, the optimal incubation time was determined in the time-course experiments at $24^{\circ} \mathrm{C}$, in which conidial germination and appressorium formation were recorded through observation with an Olympus BX41 microscope (Olympus) at $\times 400$ magnification every $2 \mathrm{~h}$ up to $12 \mathrm{~h}$ and then at 6-h intervals from 12 to $36 \mathrm{~h}$.

Effects of carbon and nitrogen sources. All chemicals were purchased from Sigma (Sigma-Aldrich, St. Louis), unless otherwise stated. $P$. citricarpa conidia were harvested as above and individually mixed with various autoclave-sterilized nutrients at a 1:3 ratio of conidial suspensions to solutions to give final

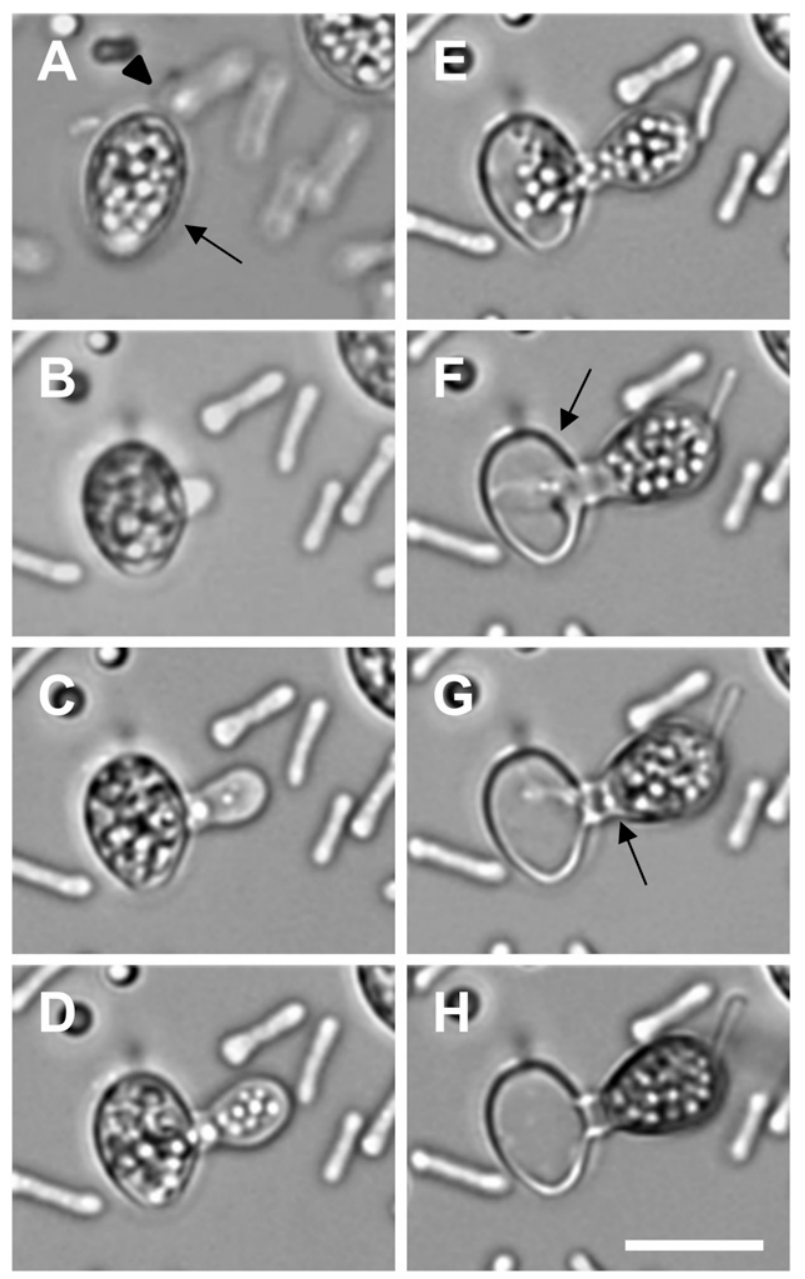

Fig. 1. Conidial germination and appressorium formation of Phyllosticta citricarpa. A, Conidia of $P$. citricarpa are surrounded by a barely visible mucoid sheath (arrow), have an apical appendage (arrowhead), and contain abundant lipid-like bodies that obscure other cytoplasmic organelles. Dumbbell-shaped spermatia are also observed in conidial suspensions. B, At $2 \mathrm{~h}$ after incubation in $1.5 \%$ 'Valencia' juice at $24^{\circ} \mathrm{C}$, a germ tube emerged from the spore and remained free of lipid-like bodies. $\mathbf{C}$, At $3 \mathrm{~h}$ after incubation, the germ tube started to swell as a sign of initiation of appressorium development. D, At 3.5 $\mathrm{h}$ after incubation, the germ tube continuously swelled, and lipid-like bodies migrated into the swollen tube. E, Within approximately $4 \mathrm{~h}$ after incubation, most lipid-like bodies had migrated into the immature appressorium. F, At $5 \mathrm{~h}$ after incubation, the appressorium developed almost completely and began to melanize. The arrow indicates the barely visible sheath surrounding the empty spore. G, At $5.5 \mathrm{~h}$ after incubation, a septum (arrow) that separates the conidium from the appressorium became discernible. $\mathbf{H}$, After $7 \mathrm{~h}$ of incubation, the melanized appressorium became clearly visible. Scale bar $=10 \mu \mathrm{m}$. concentrations indicated as follows: $75 \mathrm{mM}$ carbon sources (D-glucose, D-fructose, D-galactose and D-mannitol, sucrose, and maltose), $75 \mathrm{mM}$ nitrogen sources (ammonium acetate, ammonium chloride, ammonium sulfate, ammonium nitrate, sodium nitrate, potassium nitrate, calcium nitrate, and urea), $75 \%$ potato dextrose broth (PDB), $0.75 \%$ (wt/vol) yeast extract, and $0.75 \%$ (wt/vol) tryptone.

Effects of synthetic citrus juice. Synthetic citrus juice was prepared according to the recipe published by Cánovas et al. (1997) to determine the critical components of citrus juice for conidial germination and appressorium formation of $P$. citricarpa. Briefly, five different basal solutions were prepared and filter sterilized using $0.45-\mu \mathrm{m}$ membrane filters (Thermo Fisher Scientific) as follows (wt/vol): sugars ( $\mathrm{Su}$; glucose at $23 \mathrm{~g} /$ liter, fructose at 23 $\mathrm{g} /$ liter, and sucrose at $46 \mathrm{~g} / \mathrm{liter})$, salts $\left(\mathrm{Sa} ; \mathrm{K}_{2} \mathrm{HPO}_{4}\right.$ at $0.5 \mathrm{~g} / \mathrm{liter}$, $\mathrm{KH}_{2} \mathrm{PO}_{4}$ at $0.5 \mathrm{~g} / \mathrm{liter}, \mathrm{NH}_{4} \mathrm{Cl}$ at $0.2 \mathrm{~g} / \mathrm{liter}$, and $\mathrm{FeCl}_{3}$ at 0.001 $\mathrm{g} /$ liter), citric acid (C) at $10 \mathrm{~g} /$ liter, thiamine (T) at $1 \mathrm{mg} /$ liter, and limonin (L) at $45 \mathrm{mg} /$ liter. Various formulations of synthetic citrus juice were then prepared using these basal solutions, diluted to $2 \%$ with deionized water, adjusted to $\mathrm{pH} 3.4$ with $1 \mathrm{~N} \mathrm{HCl}$ or $1 \mathrm{~N} \mathrm{NaOH}$, and filter sterilized using 0.45 - $\mu \mathrm{m}$ membrane filters (Thermo Fisher Scientific) for the subsequent assays of conidial germination and appressorium formation

Data analysis. To evaluate the effects of citrus juice sources, carbon and nitrogen sources, and synthetic citrus juice on conidial germination and appressorium formation, a generalized linear model with a Poisson distribution and a log-link function was performed using SAS PROC GLIMMIX (SAS Institute Inc., Cary, NC, U.S.A.). In the model, the juice source was considered a fixed effect, and replication and the interaction between juice source and replication were considered random effects. Pairwise differences of least-squares means were then used to separate the treatment means at the 5\% significance level. The correlation between the juice quality (juice $\mathrm{pH}$, Brix/acid ratios, and juice oil content) and conidial germination or appressorium formation was analyzed using Pearson's correlation coefficient ( $r$ ) (SAS PROC CORR). To describe the relationship between the effect (juice concentration, juice $\mathrm{pH}$, temperature, or incubation time) and conidial germination and appressorium formation, nonlinear regression analysis was carried out using SAS PROC NLIN with the Marquardt option. The coefficient of determination $\left(r^{2}\right)$ and the root mean square error calculated by linear regression analysis between the predicted values obtained from the model and the measured values of the data set were used to evaluate the performance of models.

\section{RESULTS}

Conidial germination and appressorium formation. Conidia of $P$. citricarpa are surrounded by a barely visible mucoid sheath that extends into an apical appendage and are filled with lipid-like bodies (Fig. 1A). Conidial germination began approximately $2 \mathrm{~h}$ after incubation in $1.5 \%$ 'Valencia' juice at $24^{\circ} \mathrm{C}$ with the emergence of a germ tube (Fig. 1B). After $3 \mathrm{~h}$ of incubation, the germ tube began to swell to initiate the appressorium formation (Fig. 1C). During the process of appressorium formation, the lipidlike bodies migrated into the developing appressorium (Fig. 1D and E). Once the migration of the lipid-like bodies was complete, melanization of the appressorium began, and a septum was formed to separate the conidium from the appressorium (Fig. 1F and G). At $7 \mathrm{~h}$ postincubation, the melanized appressorium became apparent (Fig. 1H).

Citrus juice sources. Preliminary germination assays to confirm the general prerequisite of a hydrophobic surface for germination among Phyllosticta spp. (Shaw et al. 2006) revealed that $P$. ampelicida conidia germinated and formed appressoria in sterile water (39.7 and $34.5 \%$, respectively), whereas $P$. citricarpa $\mathrm{Gc} 3$ and $P$. capitalensis $\mathrm{Gm} 31$ conidia barely germinated in sterile water ( $<1$ and $1.2 \%$, respectively) (Supplementary Fig. S1). This 
result indicated that certain Phyllosticta spp. require an additional stimulus for conidial germination.

The presence of nutritional sources significantly enhanced conidial germination and appressorium formation of $P$. citricarpa (Fig. 2). The rates of conidial germination and appressorium formation were significantly higher in citrus juice sources after $24 \mathrm{~h}$
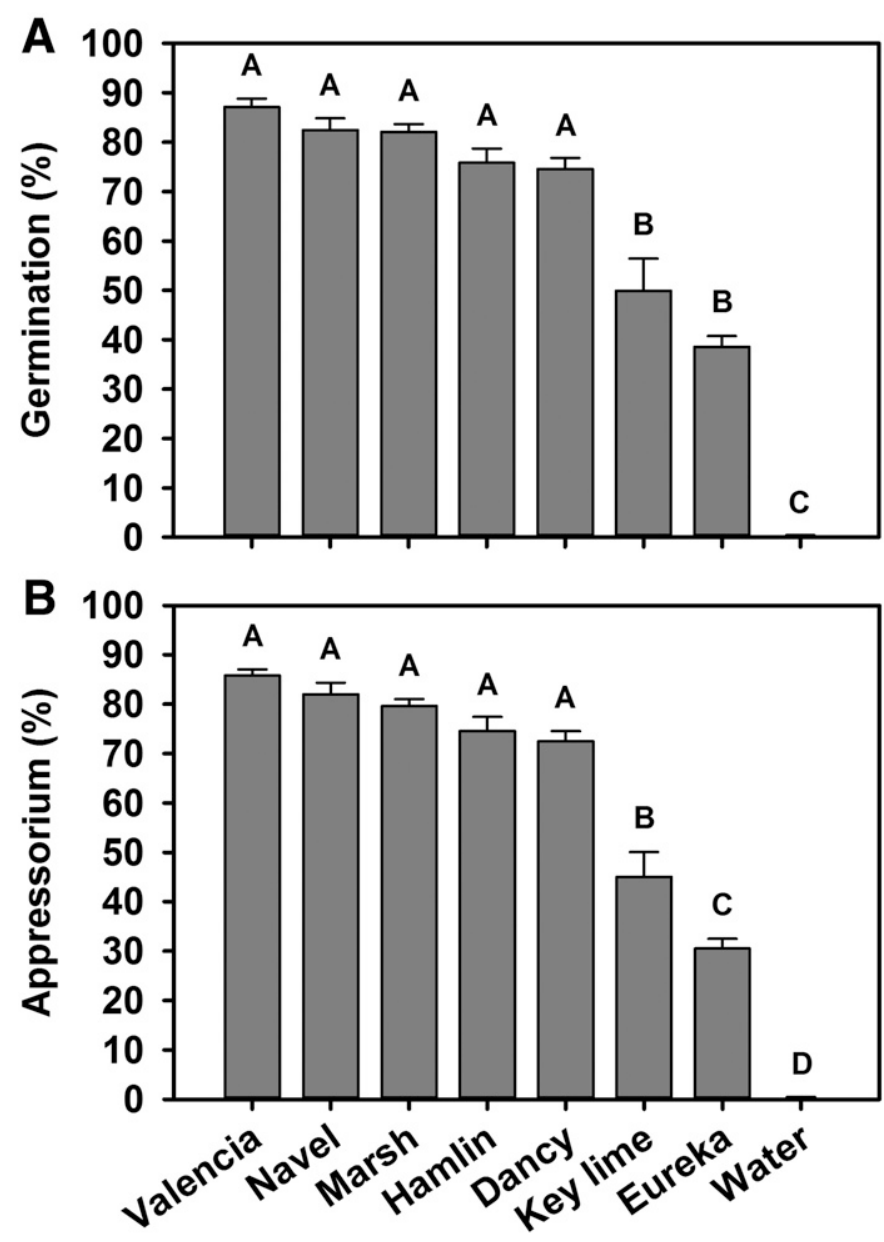

Fig. 2. Effect of various juice sources on $\mathbf{A}$, conidial germination and $\mathbf{B}$, appressorium formation of Phyllosticta citricarpa at $24^{\circ} \mathrm{C}$ after incubation for $24 \mathrm{~h}$. Each point represents the mean of three independent experiments, with five replicates of each experiment. Error bars show standard errors of the mean. Columns labeled with the same letter are not significantly different from each other according to differences of least-squares means $(P=0.05)$. Results indicate the highest germination and appressorium formation rates reached in 'Valencia' sweet orange and 'Navel' sweet orange juices, followed by 'Marsh' grapefruit, 'Hamlin' sweet orange, 'Dancy' tangerine, 'Key' lime, and 'Eureka' lemon juices. of incubation at $24^{\circ} \mathrm{C}$ than in sterile deionized water, where $<1 \%$ of germination and appressorium formation were observed (Fig. 2). Among citrus juice sources tested, 'Valencia', 'Navel', 'Marsh', 'Hamlin', and 'Dancy' juice yielded significantly greater percent conidial germination and appressorium formation ( $>70 \%)$ compared with 'Key' lime and 'Eureka' juice (Fig. 2). The pH of citrus juice sources ranged from 4.32 ('Hamlin') to 2.87 ('Key' lime) (Table 1). However, the $\mathrm{pH}$ of citrus juice sources was not correlated with conidial germination or appressorium formation with $P$ values of 0.084 and 0.073 , respectively, according to Pearson's correlation test, although germination and appressorium formation rates decreased in the low-pH juices (<3.0) of 'Key' lime and 'Eureka' lemon (Table 1). The analysis of the overall oil content in juice sources showed that the oil content ranged from $0.086 \%$ in 'Valencia' juice to $0.003 \%$ in 'Dancy' juice and no correlation between the oil content and germination and appressorium formation was observed with $P$ values of 0.465 and 0.466 , respectively (Table 1). The analysis of Brix/acid ratios of citrus juice sources revealed that 'Navel' juice had the highest Brix/acid ratio of 23.2, and 'Eureka' lemon and 'Key' lime juices had the lowest Brix/acid ratio of 1.4 (Table 1). Surprisingly, Pearson's correlation test revealed a moderate correlation between the Brix/ acid ratio and germination or appressorium formation, with $r=$ $0.783(P<0.038)$ and $0.800(P<0.031)$, respectively (Table 1$)$.

Juice concentration and $\mathbf{p H}$. The 'Valencia' juice concentration and $\mathrm{pH}$ significantly affected the germination and appressorium formation of $P$. citricarpa (Figs. 3 and 4). After incubation for $24 \mathrm{~h}$ at $24^{\circ} \mathrm{C}$, the percent conidial germination and appressorium formation increased alongside the increase of 'Valencia' juice concentrations and reached the peak at $1.5 \%$ 'Valencia' juice (89.07 and 84.73\%, respectively) (Fig. 3). As the 'Valencia' juice concentration increased from 1.5 to $12 \%$, the percentages of conidial germination and appressorium formation decreased to 69.53 and $36.73 \%$, respectively (Fig. 3). Conidial germination occurred in $1.5 \%$ 'Valencia' juice with $\mathrm{pH}$ values from 3 to 6 , and the peak germination rate was observed in the original $1.5 \%$ 'Valencia' juice with the $\mathrm{pH}$ of 3.45 (Fig. 4A). No conidial germination was observed in $1.5 \%$ 'Valencia' juice with $\mathrm{pH}<2$ or $>7$. A similar trend for appressorium formation was also observed (Fig. 4A). Furthermore, the subsequent examination of the optimal $\mathrm{pH}$ of 'Valencia' juice showed that conidial germination and appressorium formation occurred in the $\mathrm{pH}$ range of 3 to 5, with the optimal pH of 3.4 (Fig. 4B), which matched our previous observation that the optimal $\mathrm{pH}$ of 'Valencia' juice for germination and appressorium formation was approximately 3.45.

Temperature and incubation time. After $24 \mathrm{~h}$ of incubation in $1.5 \%$ 'Valencia' juice, the germination rate increased as the temperature increased from 12 to $24^{\circ} \mathrm{C}$, with the peak rate at $24^{\circ} \mathrm{C}$ $(85.33 \%)$, then decreased as the temperatures increased from 24 to $32^{\circ} \mathrm{C}$ (Fig. 5). Although a similar trend for appressorium formation was observed, the rates of appressorium formation at 12 and $32^{\circ} \mathrm{C}$

TABLE 1. Relationship between juice $\mathrm{pH}$ and conidial germination or appressorium formation of Phyllosticta citricarpa ${ }^{\mathrm{y}}$

\begin{tabular}{|c|c|c|c|c|c|}
\hline Juice source ${ }^{z}$ & Germination (\%) & Appressorium (\%) & $\mathrm{pH}$ & Brix/acid ratio & Oil $(\%)$ \\
\hline 'Valencia' sweet orange & 87.13 & 85.80 & 3.45 & 13.4 & 0.086 \\
\hline 'Hamlin' sweet orange & 75.87 & 74.53 & 4.32 & 20.5 & 0.014 \\
\hline 'Navel' sweet orange & 82.47 & 82.00 & 4.04 & 23.2 & 0.052 \\
\hline 'Marsh' grapefruit & 82.07 & 79.60 & 3.42 & 9.4 & 0.004 \\
\hline 'Dancy' tangerine & 74.60 & 72.47 & 3.74 & 14.6 & 0.003 \\
\hline 'Eureka' lemon & 38.53 & 30.53 & 2.93 & 1.4 & 0.062 \\
\hline 'Key' lime & 49.93 & 45.00 & 2.87 & 1.4 & 0.080 \\
\hline $\mathrm{CC}(r)$ for $\mathrm{pH}$ & $0.694(P=0.084)$ & $0.712(P=0.073)$ & $\ldots$ & $\ldots$ & $\ldots$ \\
\hline $\mathrm{CC}(r)$ for ratio & $0.783(P=0.038)$ & $0.800(P=0.031)$ & $\ldots$ & $\ldots$ & $\ldots$ \\
\hline $\mathrm{CC}(r)$ for oil & $-0.334(P=0.465)$ & $-0.333(P=0.466)$ & $\ldots$ & $\ldots$ & $\ldots$ \\
\hline
\end{tabular}

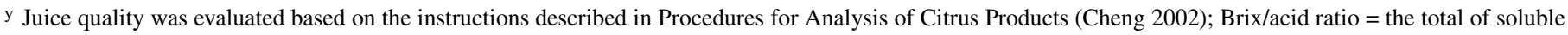
solids divided by the acid concentration.

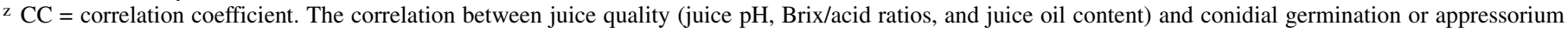
formation was evaluated using Pearson's CC $(r)$. 
were much lower than those of conidial germination (Fig. 5). No conidial germination or appressorium formation were observed at temperatures $<8^{\circ} \mathrm{C}$ or $>36^{\circ} \mathrm{C}$ (Fig. 5). Conidial germination initiated at $2 \mathrm{~h}$ after incubation in $1.5 \%$ 'Valencia' juice at $24^{\circ} \mathrm{C}$, whereas appressorium formation was observed beginning from $6 \mathrm{~h}$ after incubation (Fig. 6). The percent germination and appressorium formation reached a maximum after $18 \mathrm{~h}$ of incubation and remained constant afterward.

Carbon and nitrogen sources. Compared with $1.5 \%$ 'Valencia' juice, simple carbon and nitrogen solutions did not significantly increase conidial germination and appressorium formation over a $24-\mathrm{h}$ period of incubation at $24^{\circ} \mathrm{C}$, whereas ammonium nitrate significantly increased the germination over the water control (Table 2). In contrast, a complex carbon and nitrogen source, PDB, enhanced conidial germination (71.27\%) with no significant difference from 1.5\% 'Valencia' juice (84.27\%) (Table 2). However, appressorium formation in PDB (30\%) was significantly reduced compared with that in $1.5 \%$ 'Valencia' juice (84\%). Another complex carbon and nitrogen source, yeast extract, only supported a low level of conidial germination and appressorium formation (Table 2).

To further determine the role of the $\mathrm{pH}$ of the carbon and nitrogen sources in conidial germination and appressorium formation, the solutions were prepared and applied as above, except for the adjustment of $\mathrm{pH}$ to 3.45 with $1 \mathrm{~N} \mathrm{HCl}$ as 'Valencia' juice. Germination assays using these carbon and nitrogen solutions at $\mathrm{pH} 3.45$ displayed a similar trend in conidial germination and appressorium formation, although reductions in germination were observed in $\mathrm{pH}$-adjusted PDB and ammonium nitrate compared with unadjusted solutions (Supplementary Table S1).

Synthetic citrus juice. Over $80 \% \quad P$. citricarpa conidia germinated and formed appressoria in $1.5 \%$ complete synthetic citrus juice $(\mathrm{Su}+\mathrm{Sa}+\mathrm{C}+\mathrm{T}+\mathrm{L})$ without a significant difference from those in $1.5 \%$ 'Valencia' juice (Fig. 7). The elimination of limonin from the synthetic citrus juice $(\mathrm{Su}+\mathrm{Sa}+\mathrm{C}+\mathrm{T})$ did not have a significant effect on conidial germination and appressorium formation (Fig. 7). Within the three-component solutions ( $\mathrm{Su}+\mathrm{Sa}$ $+\mathrm{C}, \mathrm{Su}+\mathrm{Sa}+\mathrm{T}, \mathrm{Su}+\mathrm{C}+\mathrm{T}$, and $\mathrm{Sa}+\mathrm{C}+\mathrm{T}$ ) tested, conidial germination and appressorium formation were significantly reduced in the absence of sugars $(\mathrm{Sa}+\mathrm{C}+\mathrm{T})$ (Fig. 7). Although the percent germination in the solution without salts $(\mathrm{Su}+\mathrm{C}+\mathrm{T})$ was not significantly different from that observed in $1.5 \%$ 'Valencia' juice,

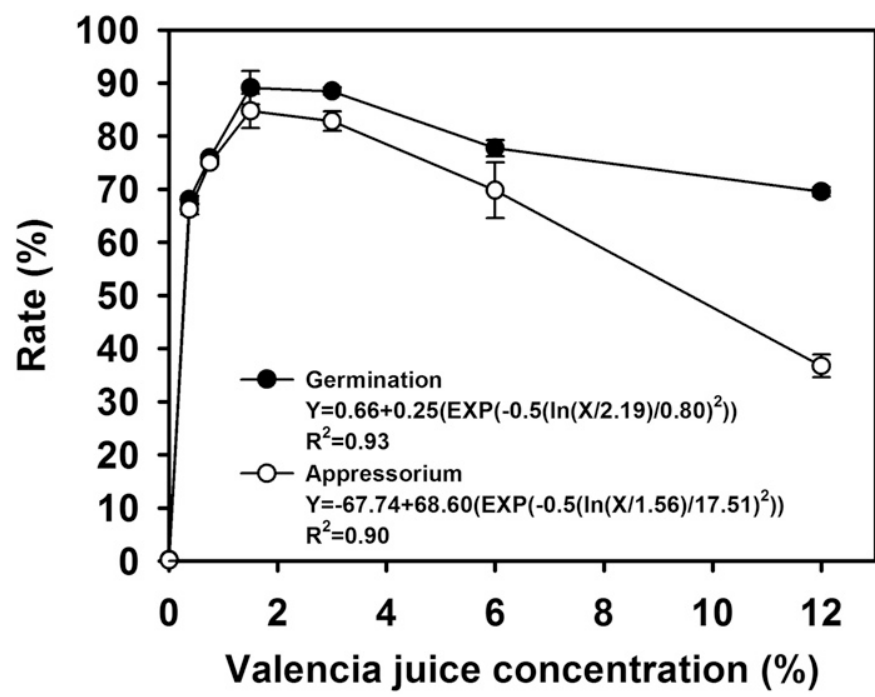

Fig. 3. Effect of 'Valencia' juice concentration on conidial germination and appressorium formation of Phyllosticta citricarpa at $24^{\circ} \mathrm{C}$ after incubation for $24 \mathrm{~h}$. Each point represents the mean of three independent experiments, with five replicates of each experiment. Error bars show standard errors of the mean. Results indicate that the optimal 'Valencia' juice concentration for germination and appressorium formation was $1.5 \%$. the appressorium formation was reduced sharply by approximately $40 \%$ in the absence of salts (Fig. 7). The use of two-component solutions $(\mathrm{Su}+\mathrm{Sa}, \mathrm{Su}+\mathrm{C}$, and $\mathrm{Sa}+\mathrm{C})$ for germination assays resulted in 30 to $40 \%$ reduction in germination and appressorium formation (Fig. 7). In addition, single-component solutions ( $\mathrm{Su}, \mathrm{Sa}$, and C) were found to stimulate only a basal level of germination and appressorium formation of approximately $20 \%$.

\section{DISCUSSION}

A successful parasitic relationship between fungal pathogens and host cells is established upon the satisfaction of many prerequisites involved in infection processes, including surface wettability of a substratum, exogenous nutrients, and environmental conditions (light, moisture, and temperature) (Blank and Murray 1998; Emmett and Parbery 1975; Kuo and Hoch 1996; Liu and Xiao 2005). Given the emergence of $P$. citricarpa in Florida (Schubert et al. 2012), elucidating which factors influence its conidial germination is not only of fundamental value in understanding the fungal biology but also of practical interest for better disease control strategies.

Previously, the universal prerequisite for conidial germination in Phyllosticta spp. was reported to be the attachment of conidia to a hydrophobic surface (Shaw et al. 2006). However, the attachment to a hydrophobic surface was not solely supportive of $P$. citricarpa
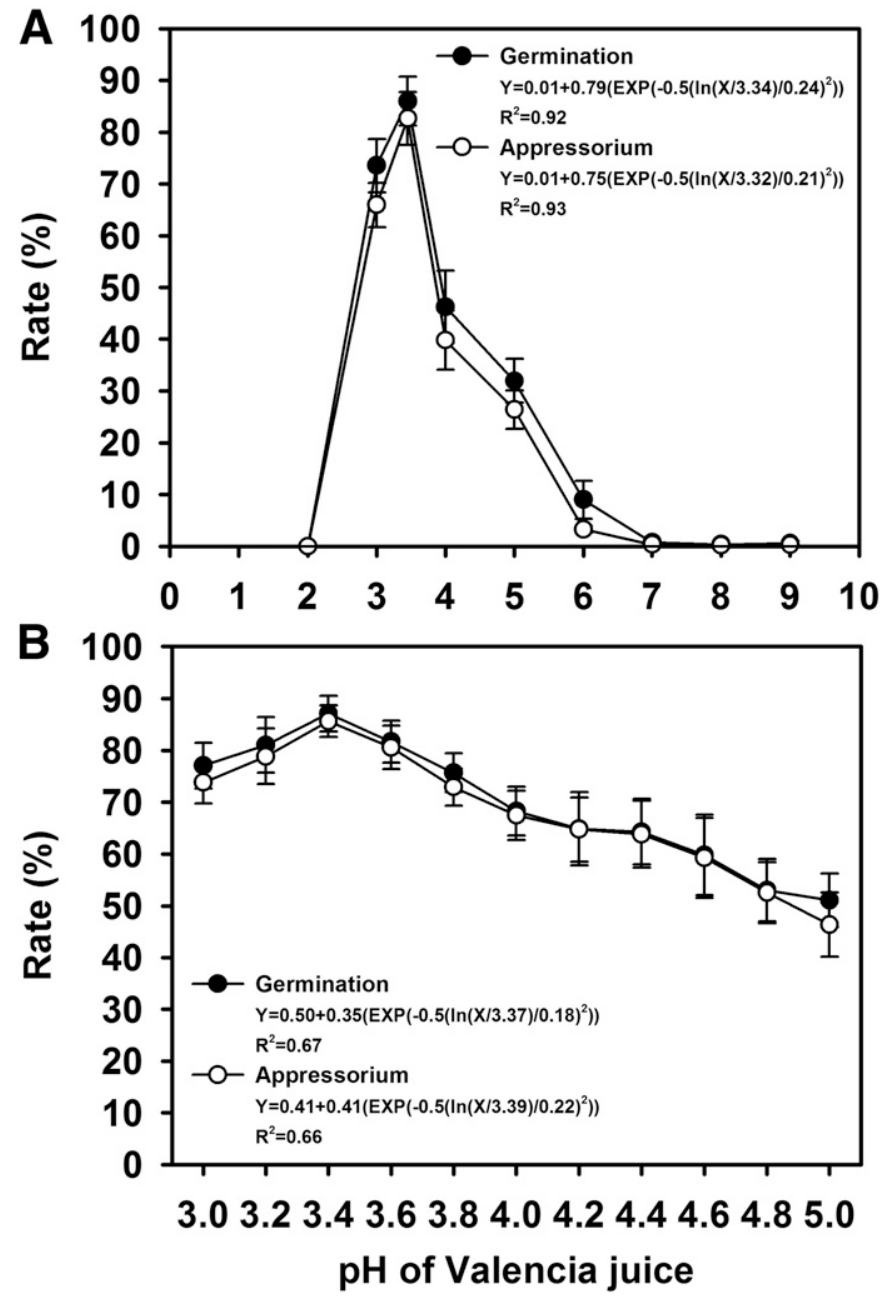

Fig. 4. Effect of $\mathrm{pH}$ on conidial germination and appressorium formation of Phyllosticta citricarpa at $24^{\circ} \mathrm{C}$ after incubation for $24 \mathrm{~h}$. The 'Valencia' juice $\mathrm{pH}$ was adjusted $\mathbf{A}$, from 2 to 9 at $1-\mathrm{pH}$ intervals and $\mathbf{B}$, from 3 to 5 at $0.2-\mathrm{pH}$ intervals with $1 \mathrm{~N} \mathrm{HCl}$ or $1 \mathrm{~N} \mathrm{NaOH}$. Each point represents the mean of three independent experiments, with five replicates of each experiment. Error bars show standard errors of the mean. Results show that the optimal pH for germination and appressorium formation was 3.45 . 
conidial germination. Its conidia rarely germinated in sterile water even on a hydrophobic surface (Kiely 1948; Korf 1998), implying additional requirements for germination. In the present study, we evaluated the effects of juices from seven citrus cultivars on conidial germination and appressorium formation of $P$. citricarpa and demonstrated that all citrus juices significantly favored conidial germination and appressorium formation, with the maximum rate of over $80 \%$ observed in $1.5 \%$ 'Valencia' juice. The requirement for additional nutrients to promote germination and the full development of appressoria has also been observed in other fungi such as Potebniamyces pyri, Penicillium digitatum, Botrytis cinerea, and Colletotrichum graminicola (Liu and Xiao 2005; Nassr and Barakat 2013; Pelser and Eckert 1977; Skoropad 1967). However, in contrast to our results, Korf (1998) reported that only approximately $60 \%$ germination of $P$. citricarpa was recorded in $1.5 \%$ 'Valencia' juice. The discrepancy in germination levels between these two studies is likely due to the different $\mathrm{pH}$ values of 'Valencia' juices used, because 'Valencia' juice with a higher $\mathrm{pH}$ value of 4.34 was used in Korf's germination assays compared with ours with a $\mathrm{pH}$ value of 3.45. Indeed, analysis of the effect of 'Valencia' juice $\mathrm{pH}$ on germination and appressorium formation clearly showed that the highest germination rate occurred in $1.5 \%$ 'Valencia' juice with a $\mathrm{pH}$ value of approximately 3.4. Moreover, Korf's observation of approximately $60 \%$ germination at $\mathrm{pH} 4.34$ matched our predicted value according to the mathematical equation (Fig. 4B), further confirming the relationship between the juice solution $\mathrm{pH}$ and conidial germination in $P$. citricarpa.

A moderate relationship between the Brix/acid ratio and conidial germination $(r=0.783)$ was revealed from the juice quality analysis test but no relationship between juice $\mathrm{pH}$ or the oil content and germination was found with the same test. In general, a Brix/acid ratio (the total of soluble solids divided by the acid concentration) is a value commonly used in the juice-processing industry to express the relationship between sweetness and acidity (Kilburn 1958). This ratio is greatly affected by citrus cultivars and fruit maturity. The acid concentration in juice decreases during the fruit ripening process whereas the Brix value remains constant or increases slightly (Kilburn 1958). Therefore, with such a small sample size $(n=7)$ and only one maturity stage of fruit used, the observation of the moderate correlation between the Brix/acid ratio and germination may have limited meaning. In this study, it was observed that 'Valencia' sweet orange, Navel sweet orange, and Marsh grapefruit juices all favored the conidial germination of $P$. citricarpa without a significant difference while the variation of the Brix/acid ratios among them was quite large, ranging from 9.4 to 23.2. To further elucidate the possible role of juice quality in germination, a set of citrus juices collected from fruit of a specific cultivar at various ripening stages should be included in a set of germination assays.

Conidial germination and appressorium formation of $P$. citricarpa were not substantially improved by most simple carbon or nitrogen sources alone, except for ammonium nitrate, which was able to support a germination rate of approximately $20 \%$. These results are likely due to the toxicity of the higher concentration $(75 \mathrm{mM})$ used in germination assays. Nassr and Barakat (2013) reported that the conidial germination of $B$. cinerea declined sharply in the presence of more than $10 \mathrm{mM}$ cations $\left(\mathrm{Ca}^{2+}, \mathrm{Mg}^{2+}, \mathrm{K}^{+}\right.$, and $\left.\mathrm{Fe}^{2+}\right)$. Because ammonium nitrate is the only tested compound containing nitrogen sources $\left(\mathrm{NH}_{4}^{+}\right.$and $\left.\mathrm{NO}_{\overline{3}}^{-}\right)$as the sole ions, the lack of those extra cations $\left(\mathrm{Ca}^{2+}, \mathrm{Na}^{+}\right.$, and $\left.\mathrm{K}^{+}\right)$or anions $\left(\mathrm{Cl}^{-}, \mathrm{CH}_{3} \mathrm{COO}^{-}\right.$, and $\left.\mathrm{SO}_{4}^{-}\right)$in ammonium nitrate may be the reason why $P$. citricarpa conidia can germinate even at the high concentration.

Given that natural citrus juice is a complex solution and its quality is largely influenced by cultivar and fruit maturity, not knowing the components in citrus juice responsible for conidial germination hampers the reproducibility of germination assays between laboratories. Therefore, in this study, a synthetic citrus juice prepared based on the recipe of Cánovas et al. (1997) was tested and shown to be as effective as the natural 'Valencia' juice in promoting conidial germination and appressorium formation. The elimination of limonin did not significantly result in reduction of conidial germination and appressorium formation, suggesting that limonin as the triterpenoid bitter principle is not essential for the germination processes of P. citricarpa. As for salts and thiamine, it was shown that the omission of salts or thiamine did not significantly affect germination. However, the appressorium formation was reduced by approximately $20 \%$ in the absence of thiamine and sharply reduced by approximately $40 \%$ without the presence of salts, suggesting that both salts and thiamine play a role in the processes of appressorium formation of $P$. citricarpa. These findings were similar to those reported by Pelser and Eckert (1977) where the mixture of macroelements, microelements, and vitamins was not required for germination of conidia but was essential for vigorous growth of germ tubes of P. digitatum.

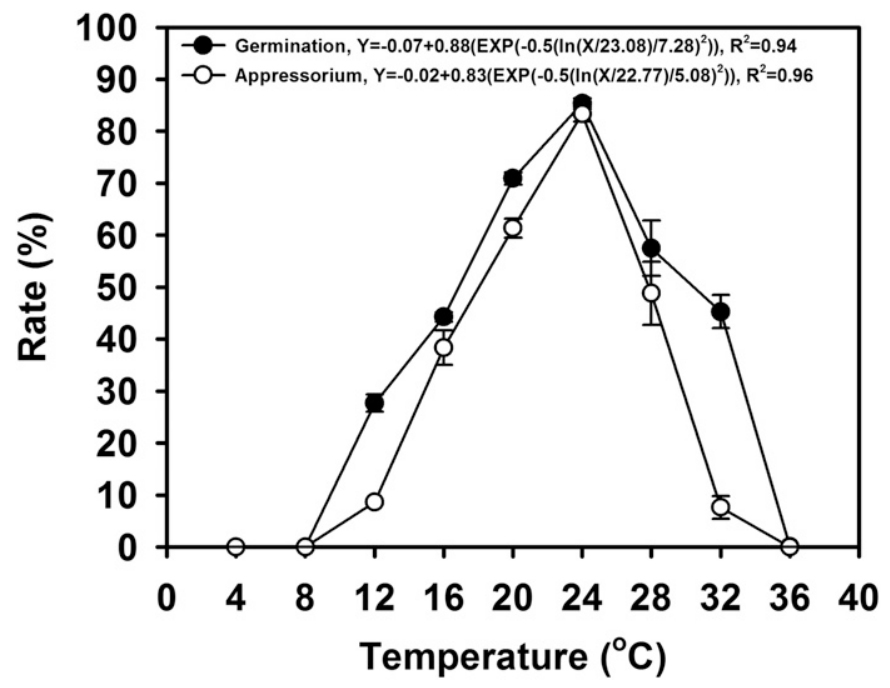

Fig. 5. Effect of temperature on conidial germination and appressorium formation of Phyllosticta citricarpa after incubation for $24 \mathrm{~h}$. Each point represents the mean of three independent experiments, with five replicates of each experiment. Error bars show standard errors of the mean. Results reveal the optimal temperature of $24^{\circ} \mathrm{C}$ for germination and appressorium formation.

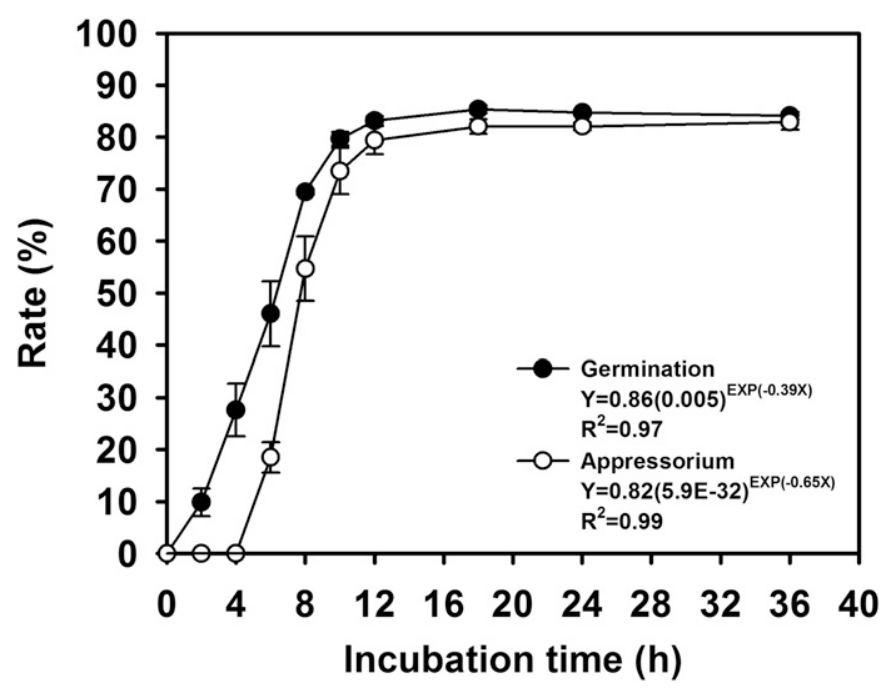

Fig. 6. Effect of incubation time on conidial germination and appressorium formation of Phyllosticta citricarpa at $24^{\circ} \mathrm{C}$. Each point represents the mean of three independent experiments, with five replicates of each experiment. Error bars show standard errors of the mean. 
The sugar solution was found to be essential to stimulate conidial germination to the level observed in 'Valencia' juice and the absence of sugars in the solution resulted in significant germination

TABLE 2. Effects of various carbon or nitrogen sources on conidial germination and appressorium formation of Phyllosticta citricarpa

\begin{tabular}{lccc}
\hline Solution & $\mathrm{pH}$ & Germination $(\%)^{\mathrm{z}}$ & Appressorium $(\%)^{\mathrm{z}}$ \\
\hline Carbon & & & \\
D-Fructose & 4.80 & $3.13 \pm 1.23 \mathrm{~d}$ & $2.60 \pm 1.10 \mathrm{~cd}$ \\
D-Glucose & 4.91 & $0.87 \pm 0.29 \mathrm{de}$ & $0.73 \pm 0.24 \mathrm{~d}$ \\
D-Galactose & 4.68 & $0.67 \pm 0.13 \mathrm{de}$ & $0.60 \pm 0.12 \mathrm{~d}$ \\
D-Mannitol & 4.74 & $0.53 \pm 0.18 \mathrm{e}$ & $0.47 \pm 0.18 \mathrm{~d}$ \\
Sucrose & 4.74 & $1.60 \pm 0.23 \mathrm{de}$ & $1.47 \pm 0.29 \mathrm{~cd}$ \\
Maltose & 4.58 & $0.40 \pm 0.12 \mathrm{e}$ & $0.33 \pm 0.07 \mathrm{~d}$ \\
Nitrogen & & & \\
Ammonium acetate & 6.67 & $0.13 \pm 0.07 \mathrm{e}$ & $0 \mathrm{~d}$ \\
Ammonium chloride & 4.72 & $1.80 \pm 0.00 \mathrm{de}$ & $1.73 \pm 0.07 \mathrm{~cd}$ \\
Ammonium sulfate & 4.90 & $1.20 \pm 0.20 \mathrm{de}$ & $0.07 \pm 0.07 \mathrm{~d}$ \\
Ammonium nitrate & 4.73 & $23.73 \pm 4.91 \mathrm{~b}$ & $22.87 \pm 4.10 \mathrm{~b}$ \\
Potassium nitrate & 5.08 & $0.07 \pm 0.07 \mathrm{e}$ & $0.07 \pm 0.07 \mathrm{~d}$ \\
Sodium nitrate & 5.18 & $0.07 \pm 0.07 \mathrm{e}$ & $0 \mathrm{~d}$ \\
Calcium nitrate & 4.96 & $1.13 \pm 0.29 \mathrm{de}$ & $0.87 \pm 0.29 \mathrm{~d}$ \\
Urea & 8.84 & $0.53 \pm 0.07 \mathrm{e}$ & $0.27 \pm 0.07 \mathrm{~d}$ \\
Complex carbon/nitrogen & & & \\
PDB & 5.01 & $71.27 \pm 1.58 \mathrm{a}$ & $30.00 \pm 3.82 \mathrm{~b}$ \\
Yeast extract & 5.75 & $9.67 \pm 1.25 \mathrm{c}$ & $4.27 \pm 2.56 \mathrm{c}$ \\
Trypton & 6.98 & $0.40 \pm 0.00 \mathrm{e}$ & $0.33 \pm 0.07 \mathrm{~d}$ \\
'Valencia' juice & 3.45 & $84.27 \pm 4.28 \mathrm{a}$ & $84.00 \pm 4.20 \mathrm{a}$ \\
Sterile deionized water & 6.59 & $0.33 \pm 0.07 \mathrm{e}$ & $0.27 \pm 0.07 \mathrm{~d}$ \\
\hline
\end{tabular}

y Final concentrations of solutions were as follows: $75 \mathrm{mM}$ carbon and nitrogen sources, $0.75 \%$ yeast extract and tryptone, $75 \%$ potato dextrose broth (PDB), and $1.5 \%$ 'Valencia' juice.

${ }^{z}$ Data are means of three independent experiments, with five replicates of each experiment \pm standard errors. Means followed by the same letter are not significantly different from each other according to differences of leastsquares means $(P=0.05)$.

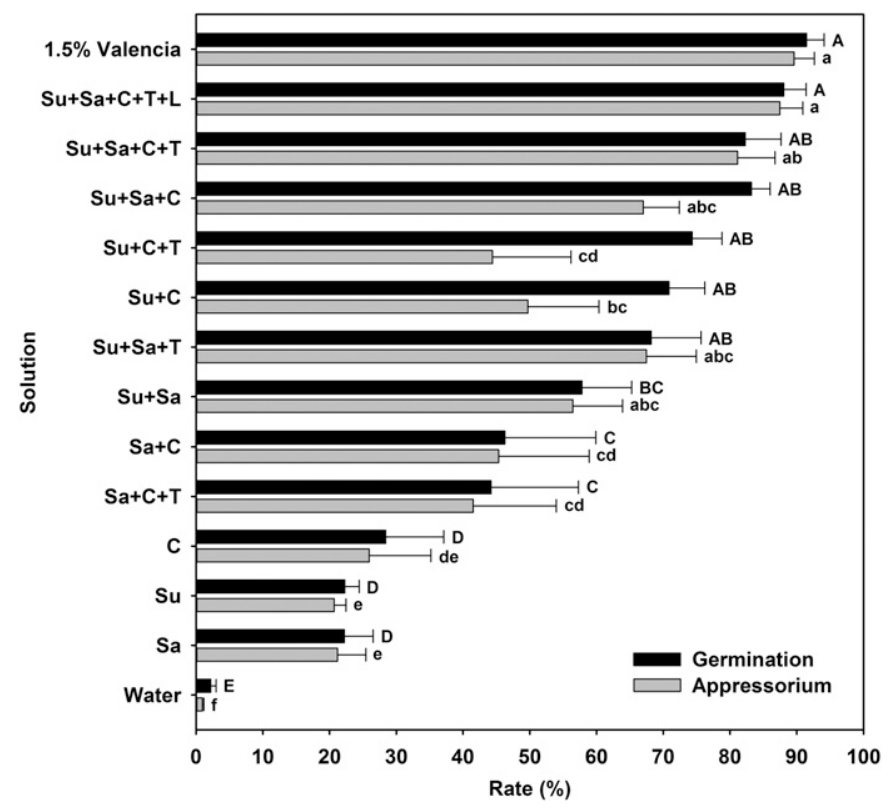

Fig. 7. Effects of synthetic citrus juice solutions on conidial germination and appressorium formation of Phyllosticta citricarpa. The synthetic citrus juice was prepared according to Cánovas et al. (1997). The final concentration of all solutions was $1.5 \%$ after being mixed with conidial suspensions at a 1:3 ratio. Each point represents the mean of three independent experiments, with five replicates of each experiment. Error bars show standard errors of the mean. Columns labeled with the same letter (uppercase and lowercase letters for germination and appressorium formation, respectively) are not significantly different from each other according to differences of least-squares means $(P=$ $0.05) . \mathrm{Su}=$ sugars $\left(\right.$ glucose, fructose, and sucrose), $\mathrm{Sa}=$ salts $\left(\mathrm{K}_{2} \mathrm{HPO}_{4}\right.$, $\mathrm{KH}_{2} \mathrm{PO}_{4}, \mathrm{NH}_{4} \mathrm{Cl}$, and $\left.\mathrm{FeCl}_{3}\right), \mathrm{C}=$ citric acid, $\mathrm{T}=$ thiamine, and $\mathrm{L}=$ limonin. reduction. Although we did not further test the effectiveness of each sugar (glucose, fructose, and sucrose) in supporting germination, Pelser and Eckert (1977) reported that glucose was superior to fructose and sucrose in stimulating conidial germination of $P$. digitatum, which is likely due to more efficient delivery of glucose into cells or easier access to glucose by constitutive enzymes in cells, and therefore suggested replacing the original sugar mixture with double the concentration of glucose without reduction of conidial germination (Pelser and Eckert 1977). In contrast, fructose was found to more efficiently stimulate germination of $B$. cinerea conidia than glucose or sucrose (Blakeman 1975; Nassr and Barakat 2013). These findings indicate that the sugar preference for stimulation of conidial germination is fungal species dependent and needs to be determined in $P$. citricarpa to further simplify the preparation of the synthetic citrus juice for germination assays.

Citric acid was shown to support $>80 \%$ of conidial germination of $P$. citricarpa (Kiely 1948) but this effectiveness of citric acid in stimulating germination has not been repeated by other studies (Korf 1998), including our own. In this study, although citric acid alone only stimulated a basal level of germination, citric acid combined with other components in the synthetic juice was found to be essential to support a high percent germination of $P$. citricarpa. This finding, along with the fact that $P$. citricarpa prefers approximately $\mathrm{pH} 3.4$ for conidial germination, indicates that citric acid may function in buffering the medium to ensure the optimal $\mathrm{pH}$ for germination. This observation is also consistent with that reported in P. digitatum by Pelser and Eckert (1977). The findings of Kiely (1948), which showed that citric acid alone was capable of stimulating germination of $P$. citricarpa, may have resulted from the effectiveness of other compounds being washed off from fruit wounds or surface during the preparation of conidial suspensions. It is also possible that $P$. capitalensis rather than $P$. citricarpa isolates were used in the study because molecular methods for species identification were not available at the time when this study was conducted.

It was found that $P$. citricarpa conidia germinated at temperatures ranging from 12 to $32^{\circ} \mathrm{C}$, with the optimal temperature at $24^{\circ} \mathrm{C}$. Korf (1998) also reported a similar temperature range for germination, with the optimal temperature at $22^{\circ} \mathrm{C}$. In comparison with mycelial growth, $P$. citricarpa can grow across a wide range of temperatures from 5 to $38^{\circ} \mathrm{C}$, with the optimal temperature at $26^{\circ} \mathrm{C}$ (Er et al. 2014). This observation is consistent with that obtained by Brodrick and Rabie (1970) and Guarnaccia et al. (2017), showing that $27^{\circ} \mathrm{C}$ is the optimal temperature for mycelial growth and symptom development. Despite the difference in the optimal temperature for conidial germination versus mycelial growth, these findings suggest that the response of conidial germination of $P$. citricarpa to temperature is in general agreement with the temperature response of mycelial growth of the fungus.

The role of melanin accumulation during appressorium development has been well characterized in Magnaporthe grisea, where it plays an important role in supporting the generation of high turgor pressure that contributes to the force required for penetration (Howard and Ferrari 1989; Howard et al. 1991). In addition, appressoria, although not as long-term survival structures, may have an auxiliary capacity to endure the adverse environmental conditions such as UV light and desiccation to increase the chance of successful infection (Emmett and Parbery 1975). These findings suggest that appressorium formation plays an important role in establishing successful fungus-plant interactions. $P$. citricarpa, similar to many other fungal pathogens such as $M$. grisea and P. ampelicida (Bourett and Howard 1990; Shaw et al. 1998), develops melanized appressoria as an essential prerequisite for successful penetration of the host cuticle. However, excess nutrients during appressorium formation of $P$. citricarpa appear to delay or inhibit its formation because approximately $60 \%$ of germinating conidia only developed long germ tubes without the formation of 
appressoria in PDB and 12\% 'Valencia' juice. The similar response of fungal conidia to excess nutrients has also been observed in Colletotrichum spp. In this work, conidia often continued germ tube elongation and branching rather than developing appressoria in the presence of high nutrient levels (Emmett and Parbery 1975). These findings imply that starvation may favor the initiation of appressorium formation. In the case of $P$. citricarpa, conidial germination requires the stimulus of additional nutrients. Therefore, under this circumstance, balancing the needs between exogenous nutrients for germination and exhaustion of cellular energy reserves for appressorium formation is critical toward the establishment of a successful fungus-plant interaction.

During our germination assays, unexpected lower germination rates occasionally occurred. This observation was also reported by Kiely (1948), in which inconsistent results with low germination rates were obtained even when fresh 0.1 to $0.5 \%$ citric acid solutions were used. These findings indicate that other factors such as the source of conidia may contribute to the inconsistent results. The first possible clue comes from studies of conidia produced by pure fungal cultures on artificial medium. Kiely (1948) mentioned that this type of conidia particularly tended to generate poor results. However, even with the use of conidia freshly harvested from pycnidia on lesions of symptomatic mature 'Valencia' fruit, inconsistent results remained, indicating that the sources (artificial medium or lesions on symptomatic fruit) where conidia were produced were probably not the cause for the inconsistent results. Therefore, other possible factors were proposed, including the environmental conditions during conidial production and the age of conidia. Kiely (1948) mentioned that the moisture condition during conidial production was critical. In this work, conidia produced from presoaked pycnidia on lesions of symptomatic fruit were more capable of germinating during the assays. Afterward, he tested the longevity of conidia by conducting germination assays over a long period of time with the same conidial source and found that the germination rate drastically decreased from approximately 80 to $20 \%$ after 5 days, indicating a quick decline of conidial germination ability and its short-lived nature (Kiely 1948). A similar age effect on conidial germination was also observed in $B$. cinerea in the study by Nassr and Barakat (2013), where a significantly lower germination rate $(67 \%)$ was recorded in 14-day-old conidia on the hydrophobic surface compared with $91 \%$ in 5-day-old conidia. However, the age effect on conidial germination of $B$. cinerea can be masked by additional nutrients because older conidia germinated as well as younger conidia in Gamborg B5 basal salt solution amended with fructose (Nassr and Barakat 2013). Given that our fungal cultures were incubated in Parafilm-sealed plates, the moisture condition during pycnidial and conidial production should not be an issue. On the other hand, because 2-week-old fungal cultures were chosen for the experiments, the probability of mixed conidial ages may be linked to the inconsistent results. This suggests that the harvest timing for $P$. citricarpa conidia produced on artificial medium should be further fine tuned to minimize inconsistency.

Recent studies have inferred that $P$. citricarpa conidia are likely the sole inoculum in citrus fields in Florida (Carstens et al. 2017; Wang et al. 2016). Given that citrus black spot management mainly relies on regular fungicide sprays, chances are that a fungicideresistant population may arise from the frequent use of a single fungicide (Hincapie et al. 2014; Stammler et al. 2013). Therefore, alternative fungicides with different modes of action would be needed to reduce the risk of resistance development. This can be achieved using a robust and convenient technique for screening the efficacy of fungicides in vitro. Indeed, this system has been successfully applied to the determination of baseline sensitivity of the Floridian population of $P$. citricarpa to quinone outside inhibitor fungicides (Hincapie et al. 2014), which will subsequently serve as the foundation for monitoring fungicide resistance in the future.

In conclusion, our study has showed that conidial germination and appressorium formation of $P$. citricarpa is nutrition and environment dependent and can reach the maximum rate when conidia are incubated on a hydrophobic surface in $1.5 \%$ 'Valencia' juice at $\mathrm{pH} 3.4$ for at least $18 \mathrm{~h}$ at $24^{\circ} \mathrm{C}$. Sugars, salts, citric acid, and thiamine are determined to be critical for germination processes of $P$. citricarpa, suggesting that the effectiveness of the natural or synthetic juice in stimulating germination is attributed to complicated interactions of many nutritional and environmental factors instead of one or few unique components. Our findings in the current study will not only contribute to increasing the reproducibility of germination assays of $P$. citricarpa between different laboratories via simplifying the preparation of the nutritional solution but also provide a further understanding of fungal biology that may be useful for developing better disease control measures.

\section{ACKNOWLEDGMENTS}

We thank M. D. Danyluk and G. A. Lundy for their advice and technical assistance in analyzing juice quality and preparing synthetic citrus juice.

\section{LITERATURE CITED}

Baayen, R. P., Bonants, P. J. M., Verkley, G., Carroll, G. C., van der Aa, H. A., de Weerdt, M., van Brouwershaven, I. R., Schutte, G. C., Maccheroni, W., Jr., Glienke de Blanco, C., and Azevedo, J. L. 2002. Nonpathogenic isolates of the citrus black spot fungus, Guignardia citricarpa, identified as a cosmopolitan endophyte of woody plants, G. mangiferae (Phyllosticta capitalensis). Phytopathology 92:464-477.

Baldassari, R. B., Wickert, E., and de Goes, A. 2008. Pathogenicity, colony morphology and diversity of isolates of Guignardia citricarpa and G. mangiferae isolated from Citrus spp. Eur. J. Plant Pathol. 120:103-110.

Blakeman, J. P. 1975. Germination of Botrytis cinerea conidia in vitro in relation to nutrient conditions on leaf surfaces. Trans. Br. Mycol. Soc. 65: 239-247.

Blank, C. A., and Murray, T. D. 1998. Influence of $\mathrm{pH}$ and matric potential on germination of Cephalosporium gramineum conidia. Plant Dis. 82:975-978.

Bourett, T. M., and Howard, R. J. 1990. In vitro development of penetration structures in the rice blast fungus Magnaporthe grisea. Can. J. Bot. 68: 329-342.

Brodrick, H. T., and Rabie, C. J. 1970. Light and temperature effects on symptom development and sporulation of Guignardia citricarpa Kiely, on Citrus sinensis (Linn) Osbeck. Phytophylactica 2:157-164.

Cánovas, M., García-Cases, L., and Iborra, J. L. 1997. Shifts in metabolism and morphology of Rhodococcus fascians when debittering synthetic citrus juices in the absence of aeration. Biotechnol. Lett. 19:1181-1184.

Carstens, E., Linde, C. C., Slabbert, R., Miles, A. K., Donovan, N. J., Li, H., Zhang, K., Dewdney, M. M., Rollins, J. A., Glienke, C., Schutte, G. C., Fourie, P. H., and McLeod, A. 2017. A global perspective on the population structure and reproductive system of Phyllosticta citricarpa. Phytopathology 107:758-768.

CBS Expert Panel. 2013. Response to EFSA panel on plant health, 2013-Draft scientific opinion on the risk of Phyllosticta citricarpa (Guignardia citricarpa) for the EU territory with identification and evaluation of risk reduction options. Online publication. http://www.citrusres. com/downloads/market-access/cbs-expert-panel-comments-efsa-pra-cbs-2013

Cheng, G. 2002. Page 192 in: Procedures for Analysis of Citrus Products, 4th ed. FMC Technologies, Inc., FMC FoodTech, Citrus Systems, Lakeland, FL.

Darnell-Smith, G. P. 1918. An account of some observations upon the lifehistory of Phoma citricarpa McAlp., the cause of the "black spot" disease in citrus fruit in New South Wales. Proc. Linn. Soc. N. S. W. 43:868-881.

de Goes, A., Baldassari, R. B., Feichtenberger, E., Aguilar-Vildoso, C. I., and Spósito, M. B. 2000. Cracked spot, a new symptom of citrus black spot (Guignardia citricarpa) in Brazil. In: 9th Int. Citrus Congress Int. Soc. Citricult. Orlando, FL.

EFSA. 2014. Scientific opinion on the risk of Phyllosticta citricarpa (Guignardia citricarpa) for the EU territory with identification and evaluation of risk reduction options. EFSA J. 12:3557.

Emmett, R. W., and Parbery, D. G. 1975. Appressoria. Annu. Rev. Phytopathol. 13:147-165.

Er, H. L., Hendricks, K., Goss, E. M., Smith, M., Schubert, T. S., Roberts, P. D., and van Bruggen, A. H. C. 2014. Isolation and biological characterization of Guignardia species from citrus in Florida. J. Plant Pathol. 96:1-13. Gareth Jones, E. B. 1994. Fungal adhesion. Mycol. Res. 98:961-981.

Guarnaccia, V., Groenewald, J. Z., Li, H., Glienke, C., Carstens, E., Hattingh, V., Fourie, P. H., and Crous, P. W. 2017. First report of Phyllosticta citricarpa and description of two new species, $P$. paracapitalensis and P. paracitricarpa, from citrus in Europe. Stud. Mycol. 87:161-185. 
Hidalgo Góngora, E. I., and Pérez Vicente, L. 2010. Diferenciación morfológica, cultural y biológica de Guignardia citricarpa y Guignardia mangiferae en frutos cítricos de Cuba. Fitosanidad (Ciudad Habana) 14: 141-152.

Hincapie, M., Wang, N.-Y., Peres, N. A., and Dewdney, M. M. 2014. Baseline sensitivity of Guignardia citricarpa isolates from Florida to azoxystrobin and pyraclostrobin. Plant Dis. 98:780-789.

Howard, R. J., and Ferrari, M. A. 1989. Role of melanin in appressorium function. Exp. Mycol. 13:403-418.

Howard, R. J., Ferrari, M. A., Roach, D. H., and Money, N. P. 1991. Penetration of hard substrates by a fungus employing enormous turgor pressures. Proc. Natl. Acad. Sci. USA 88:11281-11284.

Kiely, T. B. 1948. Preliminary studies of Guignardia citricarpa n. sp.: The ascigerous state of Phoma citricarpa McAlp. and its relation to black spot of citrus. Proc. Linn. Soc. N. S. W. 73:249-292.

Kiely, T. B. 1949. Black spot of citrus in New South Wales coastal orchards. Agric. Gaz. N. S. W. 60:17-20.

Kilburn, R. W. 1958. The taste of citrus juice I. Relationship between Brix, acid and pH. Proc. Fla. State Hortic. Soc. 71:251-254.

Korf, H. J. G. 1998. Page 72 in: Survival of Phyllosticta citricarpa, Anamorph of the Citrus Black Spot Pathogen. University of Pretoria, Pretoria, South Africa.

Kotzé, J. M. 1981. Epidemiology and control of citrus black spot in South Africa. Plant Dis. 65:945-950.

Kuo, K., and Hoch, H. C. 1996. Germination of Phyllosticta ampelicida pycnidiospores: Prerequisite of adhesion to the substratum and the relationship of substratum wettability. Fungal Genet. Biol. 20:18-29.

Lee, Y. S., and Huang, C. S. 1973. Effect of climatic factors on the development and discharge of ascospores of the citrus black spot fungus. J. Taiwan Agric. Res. 22:135-144.

Liu, Q., and Xiao, C. L. 2005. Influence of nutrient and environmental factors on conidial germination of Potebniamyces pyri. Phytopathology 95: 572-580.

McOnie, K. C. 1964. Source of inoculum of Guignardia citricarpa, the citrus black spot pathogen. Phytopathology 54:64-67.

McOnie, K. C. 1967. Germination and infection of citrus by ascospores of Guignardia citricarpa in relation to control of black spot. Phytopathology 57:743-746.

Nassr, S., and Barakat, R. 2013. Effect of factors on conidium germination of Botrytis cinerea in vitro. Int. J. Plant Soil Sci. 2:41-54.

Paul, I., van Jaarsveld, A. S., Korsten, L., and Hattingh, V. 2005. The potential global geographical distribution of Citrus Black Spot caused by Guignardia citricarpa (Kiely): Likelihood of disease establishment in the European Union. Crop Prot. 24:297-308.

Pelser, P. du T., and Eckert, J. W. 1977. Constituents of orange juice that stimulate the germination of conidia of Penicillium digitatum. Phytopathology 67:747-754.
Peres, N. A., Harakava, R., Carroll, G. C., Adaskaveg, J. E., and Timmer, L. W. 2007. Comparison of molecular procedures for detection and identification of Guignardia citricarpa and G. mangiferae. Plant Dis. 91: 525-531.

Reis, R. F., Timmer, L. W., and de Goes, A. 2006. Effect of temperature, leaf wetness, and rainfall on the production of Guignardia citricarpa ascospores and on black spot severity on sweet orange. Fitopatol. Bras. 31:29-34.

Schubert, T. S., Dewdney, M. M., Peres, N. A., Palm, M. E., Jeyaprakash, A., Sutton, B. D., Mondal, S. N., Wang, N.-Y., Rascoe, J., and Picton, D. D. 2012. First report of Guignardia citricarpa associated with citrus black spot on sweet orange [Citrus sinensis (L.) Osbeck] in North America. Plant Dis. 96:1225.

Shaw, B. D., Carroll, G. C., and Hoch, H. C. 2006. Generality of the prerequisite of conidium attachment to a hydrophobic substratum as a signal for germination among Phyllosticta species. Mycologia 98:186-194.

Shaw, B. D., Kuo, K., and Hoch, H. C. 1998. Germination and appressorium development of Phyllosticta ampelicida pycnidiospores. Mycologia 90: 258-268.

Skoropad, W. P. 1967. Effect of temperature on the ability of Colletotrichum graminicola to form appressoria and penetrate barley leaves. Can. J. Plant Sci. 47:431-434

Spósito, M. B., Amorim, L., Bassanezi, R. B., Bergamin Filho, A., and Hau, B. 2008. Spatial pattern of black spot incidence within citrus trees related to disease severity and pathogen dispersal. Plant Pathol. 57:103-108.

Spósito, M. B., Amorim, L., Bassanezi, R. B., Yamamoto, P. T., Felippe, M. R., and Czermainski, A. B. C. 2011. Relative importance of inoculum sources of Guignardia citricarpa on the citrus black spot epidemic in Brazil. Crop Prot. 30:1546-1552.

Spósito, M. B., Amorim, L., Ribeiro, P. J., Jr., Bassanezi, R. B., and Krainski, E. T. 2007. Spatial pattern of trees affected by black spot in citrus groves in Brazil. Plant Dis. 91:36-40.

Stammler, G., Schutte, G. C., Speakman, J., Miessner, S., and Crous, P. W. 2013. Phyllosticta species on citrus: Risk estimation of resistance to QoI fungicides and identification of species with cytochrome $b$ gene sequences. Crop Prot. 48:6-12.

Wang, N.-Y., Zhang, K., Huguet-Tapia, J. C., Rollins, J. A., and Dewdney, M. M. 2016. Mating type and simple sequence repeat markers indicate a clonal population of Phyllosticta citricarpa in Florida. Phytopathology 106: 1300-1310.

Whiteside, J. O. 1967. Sources of inoculum of the black spot fungus, Guignardia citricarpa, in infected Rhodesian orchards. Rhod. Zam. Mal. J. Agric. Res. 5:171-177.

Yonow, T., Hattingh, V., and de Villiers, M. 2013. CLIMEX modelling of the potential global distribution of the citrus black spot disease caused by Guignardia citricarpa and the risk posed to Europe. Crop Prot. 44: $18-28$ 